\title{
Susceptibility of olive fruit fly, Bactrocera oleae (Diptera: Tephritidae) pupae to entomopathogenic nematodes
}

\author{
Giulia Torrini*, Giuseppe Mazza, Claudia Benvenuti, Pio Federico Roversi \\ Research Centre for Plant Protection and Certification (CREA-DC), Via Lanciola 12/A, Cascine del Riccio, 50125 Firenze, Italy
}

Vol. 57, No. 3: 318-320, 2017

DOI: 10.1515/jppr-2017-0030

Received: May 11, 2017

Accepted: July 18, 2017

${ }^{*}$ Corresponding address:

giulia.torrini@crea.gov.it

\begin{abstract}
The olive fruit fly Bactrocera oleae is one of the most serious and economically damaging insects worldwide, affecting the quality and quantity of both olive oil and table olives. Laboratory bioassays were conducted for the first time to evaluate the susceptibility of $B$. oleae pupae to two entomopathogenic nematodes (EPN) species, Steinernema carpocapsae and Heterorhabditis bacteriophora. The nematodes tested caused pupal mortality of $62.5 \%$ and $40.6 \%$, respectively. The most noteworthy result was obtained with S. carpocapsae which was able to infect $21.9 \%$ of the emerged adults. Since this tephritid fly spent several months in the soil as pupa, the use of EPNs could be a promising method to control this pest.
\end{abstract}

Key words: biological control, fruit flies, Heterorhabditis, olive, Steinernema, Tephritidae

\section{Introduction}

Olive cultivation constitutes a key element of the Mediterranean agricultural sector. Italy ranks second in the world (after Spain), producing approximately $2 \mathrm{mln} \mathrm{t}$ of olive fruit, harvested from $1,156,784$ ha (FAOSTAT 2015). Like many other crops, olive trees are affected by a wide number of pests. Among them, the most serious and economically damaging insect worldwide is the olive fruit fly, Bactrocera oleae (Rossi, 1790) (Diptera: Tephritidae). Over the last 40 years, the principal method of managing this insect pest has been through the use of conventional pesticides, particularly organophosphates. Recently, even though most pest management strategies still rely on the use of synthetic pesticides, elevated awareness of negative impacts due to the use of such products on the environment and human health have resulted in efforts to reduce reliance on chemical controls (Skouras et al. 2007; Amvrazi and Albanis 2009).

In order to reduce the use of insecticides, alternative and environmentally friendly plant protection methods are constantly being developed (Daane and
Johnson 2010). This may include the use of entomopathogenic organisms, such as entomopathogenic nematodes (EPNs) of the genera Steinernema and Heterorhabditis, which are widely regarded as promising biological control agents for a broad range of insect pests with life stages in the soil and cryptic habitats (Grewal et al. 2005).

Third instar larvae (Yee and Lacey 2003; Toledo et al. 2005; Barbosa-Negrisoli et al. 2009; Malan and Manrakhan 2009; Rohde et al. 2012; Langford et al. 2014; Shaurub et al. 2015) and pupae (Barbosa-Negrisoli et al. 2009) of several tephritid flies were reported to be susceptible to EPNs. To date, only one laboratory study has been carried out by Sirjani et al. (2009) on the olive fruit fly. They evaluated the susceptibility of the thirdinstar (pre-pupal) stage of $B$. oleae to six commercially available EPNs.

Under laboratory conditions we determined for the first time the susceptibility of $B$. oleae pupae to two EPN species, the most frequently used Steinernema carpocapsae (Weiser, 1955) and Heterorhabditis bacteriophora Poinar, 1976. 


\section{Materials and Methods}

Bactrocera oleae pupae used in the experiments were obtained from naturally infested fruit collected from trees in an organic olive grove in Impruneta (Florence, Tuscany, Central Italy) in September 2016. Harvested olives were stored on Petri dishes at $4^{\circ} \mathrm{C}$ before being used and pupae were extracted from olives with sterilized forcipes and used within one week from collection.

The susceptibility of B. oleae pupae was tested with two Italian EPNs: Steinernema carpocapsae ItS-CAO1 (collection of CREA-DC, Torrini et al. 2014) (SCC) and Heterorhabditis bacteriophora ItH-LU1 (collection of the Section of Entomology and Zoology - DISSPA, University of Bari, Tarasco et al. 2015) (HB). These nematode species were reared at $24^{\circ} \mathrm{C}$ in greater wax moth Galleria mellonella L. (Lepidoptera: Pyralidae) larvae and the infective juveniles (IJs) that emerged from cadavers were recovered using modified White traps (Kaya and Stock 1997). After storage at $12^{\circ} \mathrm{C}$ for 2 weeks, they were kept at $20^{\circ} \mathrm{C}$ for $24 \mathrm{~h}$ prior to testing.

The susceptibility assays with $B$. oleae pupae were performed in 24-well plates $\left(\mathrm{COSTAR}^{\circledR}\right.$, Corning, New York), filled with about $2 \mathrm{~g}$ of sterile sandy loam soil ( $\mathrm{pH}$ 5.8-5.9).

A single pupa was inserted into the bottom of each well; $100 \mathrm{IJs} / 0.5 \mathrm{ml}$ of distilled water were inoculated onto the soil surface ( $n=32$ for each strain). In the control $(n=32)$, only sterile water was added to each well. Wells were incubated in the dark at $20 \pm 2^{\circ} \mathrm{C}$ and $60-80 \%$ relative humidity $(\mathrm{RH})$. Adult emergence and mortality were recorded daily for a period of 15 days. Dead pupae and adults were dissected at the end of the period to assess nematode infection. The mortality caused by EPNs was compared by means of contingency table analysis and the $\chi^{2}$ test.

\section{Results}

The two EPNs caused higher cumulative mortality than the control, where no infection was observed $\left(\chi^{2}=28.537 ; \mathrm{df}=2 ; \mathrm{p}=0.0001\right)$. In particular, SCC induced $62.5 \%$ and HB $40.6 \%$ more mortality than the control $\left(\chi^{2}=29.091 ; \mathrm{df}=1 ; \mathrm{p}=0.0001\right.$ and $\chi^{2}=16.314$; $\mathrm{df}=1 ; \mathrm{p}=0.0001$, respectively). However, there was no difference in pupal mortality between the two EPNs $\left(\chi^{2}=3.065 ; \mathrm{df}=1 ; \mathrm{p}=0.08\right)$.

Interestingly, while in $\mathrm{HB}$ the EPN caused the death of pupae in SCC we found a $21.87 \%$ mortality in emerged adults, probably infected during the emergence from the bottom to the top of each well.

Differences in pupae appearance were observed. The ones infected by H. bacteriophora developed a typical red colour due to the pigment produced by the enteric bacteria Photorhabdus luminescens, while the

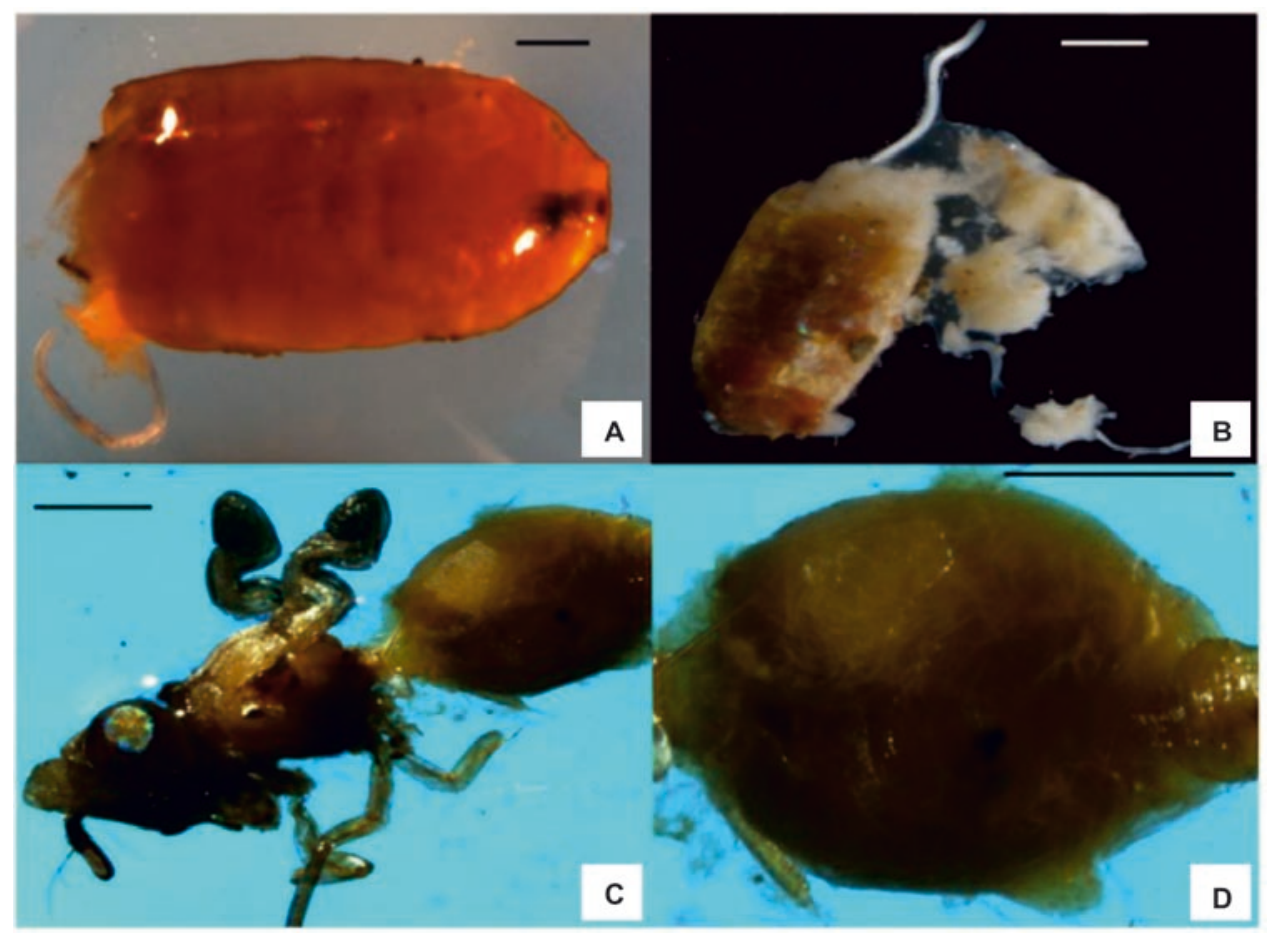

Fig. 1. Dead Bactrocera oleae pupa infected by: Heterorhabditis bacteriophora (A) and Steinernema carpocapsae (B). Dead Bactrocera oleae adult killed by S. carpocapsae (C) and a detail of entomopathogenic nematode strains (EPNs) infection inside the abdomen (D) (scale bars $=1 \mathrm{~mm}$ ) 
pupae with $S$. carpocapsae maintained a light-brown coloration (Forst and Nealson 1996; Singh et al. 2012) (Fig. 1A and B).

Steinernema carpocapsae also caused mortality of the B. oleae emerged adults. Dead adults showed wings that were not fully spread (Fig. 1C), and adult and juvenile nematodes in the entire body (e.g. abdomen; Fig. 1D).

\section{Discussion}

For the first time it was shown that B. oleae pupae are susceptible to the EPNs which were tested. Even though the olive fruit fly is economically important, only one laboratory study on the third-instar stage had been previously performed (Sirjani et al. 2009).

All of the studies conducted on tephritid flies have shown that larvae are the most susceptible stage to EPNs infection (i.e. Yee and Lacey 2003; BarbosaNegrisoli et al. 2009; Langford et al. 2014; Shaurub et al. 2015). However, in the majority of olive groves in Italy, larvae drop onto and enter the soil at the end of autumn or in winter, when the temperatures are too low to use EPNs. The important results obtained in this study, regarding the capability of EPNs to cause mortality of $B$. oleae pupae and adults, give a new perspective in the integrated management of olive fruit flies. Indeed, EPNs could be applied beneath fruit tree canopies (Shaurub et al. 2015) at the beginning of spring, when adults emerge from the soil.

Further studies are necessary to identify the optimum climatic factors for $H$. bacteriophora and $S$. carpocapsae in order to obtain the highest infection rates of $B$. oleae. More research is required to assess the mechanism of nematode penetration into the pupae and the possibility of using these nematodes in the control of B. oleae under field conditions.

\section{Acknowledgements}

The authors are grateful to Prof. Eustachio Tarasco (DISSPA) for providing the Heterorhabditis bacteriophora strain. We also wish to thank Jeffrey Shelley (Texas) for the English revision and Sauro Simoni for suggestions about the statistical analysis.

\section{References}

Amvrazi E.G., Albanis T.A. 2009. Pesticide residue assessment in different types of olive oil and preliminary exposure assessment of Greek consumers to the pesticide residues detected. Food Chemistry 113 (1): 253-261. DOI: 10.1016/j. foodchem.2008.06.073

Barbosa-Negrisoli C.R.C., Garcia M.S., Dolinski C., Negrisoli Jr. A.S., Bernardi D., Nava D.E. 2009. Efficacy of indigenous entomopathogenic nematodes (Rhabditida: Heterorhabditidae, Steinernematidae), from Rio Grande do Sul Brazil, against Anastrepha fraterculus (Wied.) (Diptera: Tephritidae) in peach orchards. Journal of Invertebrate Pathology 102 (1): 6-13. DOI: 10.1016/j.jip.2009.05.005

Daane K.M., Johnson M.W. 2010. Olive fruit fly: managing an ancient pest in modern times. Annual Review of Entomology 55: 151-69. DOI: 10.1146/annurev.ento.54.110807.090553

FAOSTAT. 2015. Available on: http://faostat3.fao.org/browse/Q/ QC/E [Accessed: March 03, 2017]

Forst S., Nealson K. 1996. Molecular biology of the symbioticpathogenic bacteria Xenorhabdus spp. and Photorhabdus spp. Microbiological reviews 60 (1): 21-43.

Grewal P.S., Ehlers R-U., Shapiro-Ilan D.I. 2005. Nematodes as Biocontrol Agents. CABI Publishing, Cambridge, UK, 528 pp.

Kaya H.K., Stock S.P. 1997. Techniques in insect nematology. p. 281-324. In: "Manual Techniques in Insect Pathology" (L.A. Lacey, ed.). Academic Press, London, UK.

Langford E.A., Nielsen U.N., Johnson S.N., Riegler M. 2014. Susceptibility of Queensland fruit fly, Bactrocera tryoni (Froggatt) (Diptera: Tephritidae), to entomopathogenic nematodes. Biological Control 69: 34-39. DOI: 10.1016/j. biocontrol.2013.10.009

Malan A.P., Manrakhan A. 2009. Susceptibility of the Mediterranean fruit fly (Ceratitis capitata) and the Natal fruit fly (Ceratitis rosa) to entomopathogenic nematodes. Journal of Invertebrate Pathology 100: 47-49. DOI: 10.1016/j. jip.2008.09.007

Rohde C., Moino Jr. A., Carvalho F.D., da Silva M.A.T. 2012. Selection of entomopathogenic nematodes for the control of the fruit fly Ceratitis capitata (Diptera: Tephritidae). Revista Brasileira de Ciências Agrárias 7: 797-802.

Shaurub E.H., Soliman N.A., Hashem A.G., Abdel-Rahman A.M. 2015. Infectivity of four entomopathogenic nematodes in relation to environmental factors and their effects on the biochemistry of the Medfly Ceratitis capitata (Wied.) (Diptera: Tephritidae). Neotropical Entomology 44 (6): 610-618. DOI: 10.1007/s13744-015-0332-3

Singh S., Eric M., Floyd I., Leonard H.D. 2012. Characterization of Photorhabdus luminescens growth for the rearing of the beneficial nematode Heterorhabditis bacteriophora. Indian Journal of Microbiology 52 (3): 325-331. DOI: 10.1007/ s12088-011-0238-7

Sirjani F.O., Lewis E.E., Kaya H.K. 2009. Evaluation of entomopathogenic nematodes against the olive fruit fly, Bactrocera oleae (Diptera: Tephritidae). Biological Control 48 (3): 274-280. DOI: 10.1016/j.biocontrol.2008.11.002

Skouras P.J., Margaritopoulos J.T., Seraphides N.A., Ioannides I.M., Kakani E.G., Mathiopoulos K.D., Tsitsipis J.A. 2007. Organophosphate resistance in olive fruit fly, Bactrocera oleae, populations in Greece and Cyprus. Pest Management Science 63 (1): 42-48. DOI: 10.1002/ps.1306

Tarasco E., Clausi M., Rappazzo G., Panzavolta T., Curto G., Sorino R., Oreste M., Longo A., Leone D., Tiberi R., Vinciguerra M.T., Triggiani O. 2015. Biodiversity of entomopathogenic nematodes in Italy. Journal of Helminthology 89 (3): 359-366. DOI: 10.1017/S0022149X14000194

Toledo J., Ibarra J.E., Liedo P., Gomez A., Rasgado M.A., Williams T. 2005. Infection of Anastrepha ludens (Diptera: Tephritidae) larvae by Heterorhabditis bacteriophora conditions. Biocontrol Science and Technology 15 (6): 627-634. DOI: 10.1080/09583150500089049

Torrini G., Landi S., Benvenuti C., De Luca F., Fanelli E., Troccoli A., Tarasco E., Bazzoffi P. 2014. Morphological and molecular characterization of a Steinernema carpocapsae (Nematoda Steinernematidae) strain isolated in Veneto region (Italy). Redia 97: 89-94.

Yee W.L., Lacey L.A. 2003. Stage-specific mortality of Rhagoletis indifferens (Diptera: Tephritidae) exposed to three species of Steinernema nematodes. Biological Control. 27 (3): 349-356. DOI: 10.1016/S1049-9644(03)00029-X 